\title{
Respiratory events with sugammadex vs. neostigmine following laparoscopic sleeve gastrectomy: a prospective pilot study assessing neuromuscular reversal strategies
}

\author{
Shmuel Evron ${ }^{1}$, Yuri Abelansky ${ }^{1}$, Tiberiu Ezri ${ }^{1}$, Alexander Izakson ${ }^{2}$ \\ ${ }^{1}$ Department of Anesthesia, Edith Wolfson Medical Center, Holon, Affiliated with Sackler Medical School, Tel Aviv University, Israel \\ ${ }^{2}$ Department of Anesthesia, Sieff Medical Center, Faculty of Medicine in the Galilee, Bar-Ilan University, Safed Israel
}

\begin{abstract}
Abdominal surgery in obese patients may be associated with pulmonary morbidity, and mortality. Some patients may arrive in the PACU with residual paralysis.

The purpose of this study was to find out if there was an association between the type of muscle relaxant reversal agent and the development of postoperative respiratory events in patients undergoing laparoscopic sleeve gastrectomy surgery.

Methods: From September 2012 to February 2013, in a prospective randomized pilot study, two different muscle relaxant reversal agents were administered at the end of surgery in 57 patients undergoing laparoscopic sleeve gastrectomy: sugammadex $2 \mathrm{mg} / \mathrm{kg}$ (32 patients) vs. neostigmine $2.5 \mathrm{mg}$ ( 25 patients). We compared the occurrence of early and late respiratory events/complications by the type of reversal agent. Postoperative respiratory rate, oxyhemoglobin saturation $\left(\mathrm{SpO}_{2}\right)$, number of patients with $\mathrm{SpO}_{2}$ lower than $95 \%$ in $\mathrm{PACU}$, the minimum value of $\mathrm{SpO}_{2}$ in $\mathrm{PACU}$, train-of four counts (TOF) before reversal, unexpected ICU admissions, duration of hospitalization and incidence of reintubation were recorded.

Results: $\mathrm{SpO}_{2}$ in the PACU was significantly lower in the neostigmine group - $\left.95.80( \pm 0.014)\right)$ vs. in sugammadex group - $96.72( \pm 0.011)(\mathrm{p}<0.01)$, despite a lower TOF count measured in the sugammadex group before reversal, meaning a deeper level of residual relaxation in this group before the administration of the reversal agent $(2.53 \pm 0.98$ vs. $3.48 \pm 0.58 \mathrm{p}<0.01)$. Also, the minimal $\mathrm{SpO}_{2}$ was significantly lower in the PACU in the neostigmine group: $93 \%$ vs. $94 \%(p=0.01)$. Respiratory rates were not different. After the administration of reversal, both groups had TOF counts of 4 with no fade assessed visually. There were no postoperative respiratory events or complications.

Conclusions: The use of sugammadex (as compared to neostigmine) as a reversal agent following laparoscopic sleeve gastrectomy surgery was associated with higher postoperative $\mathrm{SpO}_{2}$ despite the lower TOF count before the administration of reversal agent. Despite the statistical difference in $\mathrm{SpO}_{2}$, its clinical importance seems to be minimal. The lack of difference in the other measured variables may stem from the small number of patients studied (pilot).
\end{abstract}

Keywords: muscle relaxants, reversal, sugammadex, neostigmine, respiratory events

\section{Introduction}

The worldwide increase in the incidence of obesity in the last decades has been associated with metabolic, respiratory and cardiovascular complications [1-5] leading to an increased demand for bariatric surgeries

Address for correspondence:

Tiberiu Ezri, MD

Department of Anesthesia

Wolfson Medical Center

Halochamim street 62

Holon 58100, Israel

E-mail: tezri@bezeqint.net
[6-9]. General anesthesia for these surgeries has been associated with complications including respiratory failure [10-15], need for unplanned intensive care unit, prolonged hospitalization and increased mortality [16]. The need for high doses of neuromuscular blocking agents in these surgeries may cause residual paralysis and consequently critical respiratory events and late complications such as hypoxemia, pneumonia, atelectasis and the need for reintubation [17-21]. Neostigmine is unable to completely reverse deep neuromuscular blockade and may be associated with muscarinic side effects [22-26]. 
Sugammadex (Bridion ${ }^{(\mathrm{R})}$ Merk Sharp and Dohme (MSD), Oss, the Netherlands), a gamma-cyclodextrin is a novel agent for reversal of the aminosteroidal (rocuronium, vecuronium and to a lesser degree, pancuronium) non-depolarising neuromuscular blockade [22]. It has been proven to have benefits over neostigmine [23-26].

The objective of this prospective, pilot study was to compare the effects of neostigmine vs. sugammadex on critical respiratory events and late respiratory complications in morbidly obese patients undergoing laparoscopic sleeve gastrectomy surgery.

\section{Methods}

This randomized pilot trial was conducted at The Edith Wolfson Medical Center from September 2012 to February 2013 on patients undergoing elective laparoscopic sleeve gastrectomy under general anesthesia with rocuronium induced neuromuscular blockade. The study was approved by the Institutional Review Board of Wolfson Medical Center, Hollon, Israel. All patients signed a written informed consent form before enrolment in the study. Inclusion criteria were age $\geq 18$ yrs and ASA classes I-III. Exclusion criteria were neuromuscular disorders, known or expected difficult intubation, renal or liver disease, family history of malignant hyperthermia, pregnancy or breast feeding and allergy to non depolarizing blocking agents, sugammadex, opioids and other anesthetic drugs.

Patients were randomly assigned using computer generated randomization to receive either neostigmnine $2.5 \mathrm{mg}$ with atropine sulfate $1 \mathrm{mg}$ or sugammadex 2 $\mathrm{mg} / \mathrm{kg}$. Neuromuscular relaxation depth was qualitatively assessed by TOF count from the ulnar nerve. Anesthesia was induced with propofol $2 \mathrm{mg} / \mathrm{kg}$, fentanyl $1 \mu \mathrm{g} / \mathrm{kg}$ and rocuronium $0.6 \mathrm{mg} / \mathrm{kg}$ to facilitate endotracheal intubation. When gastroesophageal reflux was a concern, rapid sequence induction using succinylcholine $1 \mathrm{mg} / \mathrm{kg}$ was employed. For maintenance of anesthesia we used boluses of $50 \mu \mathrm{g}$ fentanyl as deemed necessary, propofol infusion (TIVA) 100-200 $\mu \mathrm{g} / \mathrm{kg} / \mathrm{min}$ and repetitive doses of rocuronium bromide $0.2 \mathrm{mg} / \mathrm{kg}$ in order to keep a TOF count of 0 or 1 during the surgical procedure. At the end of surgery, either sugammadex $2 \mathrm{mg} / \mathrm{kg}$ total body weight or neostigmine $2.5 \mathrm{mg}$ with atropine sulfate were administered to antagonize the effect of neuromuscular blocking agents. All patients required a TOF count of at least 2 before the administration of the reversal agent. Muscle strength was also assessed on the operating table, before extubation, for clinical signs of residual neuromuscular block (head lift and hold-up for at least five seconds and hand grip). These tests were not repeated in the PACU and TOF monitoring was not continued during the postoperative follow-up.

In the PACU, heart rate, blood pressure, respiratory rate/min and $\mathrm{SpO}_{2}$ were recorded at the admission to the PACU and every 10 min thereafter until discharge. Values of $\mathrm{SpO}_{2}$ and respiratory rate were analyzed during the first PACU hour.

The mean and minimal $\mathrm{SpO}_{2}$ and number of events with $\mathrm{SpO}_{2}<95 \%$ were also recorded. Hypoventilation $(<10 \mathrm{breath} / \mathrm{min})$ and tachypnea $(>20 \mathrm{breath} / \mathrm{min})$ were also recorded.

Immediate and late respiratory adverse events in the PACU were also recorded including respiratory distress, upper airway obstruction, aspiration, need for reintubation, unplanned admission to the intensive care unit and prolonged hospitalization.

\section{Data analysis}

Analysis of data was carried out using SPSS 9.0 statistical analysis software (SPSS Inc. Chicago, IL, USA). For continuous variables, descriptive statistics were calculated and reported as means \pm standard deviations. Normality of distribution of continuous variables was assessed using the Kolmogorov-Smirnov test (cut-off at $\mathrm{p}=0.01$ ). Categorical variables such as treatment group and symptoms were described using frequency distributions and are presented as frequency $(\%)$.

The t test for independent samples was used to compare continuous variables between subjects by treatment group. Chi square or Fisher exact tests used to assess associations between treatment group and other categorical variable. All tests were two-sided and considered significant at $\mathrm{p}<0.05$.

When making multiple measures, the rate of type I error is increased. Therefore, repeated measures analysis was performed first and only if significant overall difference was detected and if post hoc, pair wise comparisons could be made.

\section{Results}

The data from 57 patients were analyzed. There were 32 patients in the sugammadex group and 25 in the neostigmine group. Table 1 shows the demographic data. Sex, smoking habits, ASA physical status, BMI and duration of hospitalization did not differ statistically. Four patients were intubated following succinylcholine administration, two in each group.

Table 2 shows the TOF count before reversal and respiratory parameters. Sugammadex patients had lower TOF counts before reversal but higher mean and minimal $\mathrm{SpO}_{2}$.

A decrease in $\mathrm{SpO}_{2}<95 \%$ was recorded in one patient after sugammadex and three after neostigmine. One neostigmine patient with a COPD background 
Table 1. Demographic data

\begin{tabular}{llll}
\hline Parameter & Neostigmine & Sugammadex & $\mathrm{p}$ \\
\hline Age (years) & $45 \pm 13$ & $42 \pm 13$ & 0.54 \\
Sex - Women $\%$ & 65 & 56 & 0.55 \\
Height $-\mathrm{cm}$ & $164 \pm 14$ & $166 \pm 11$ & 0.60 \\
Weight $-\mathrm{kg}$ & $127 \pm 23$ & $120 \pm 21$ & 0.24 \\
BMI $-\mathrm{kg} / \mathrm{m}^{2}$ & $44 \pm 5$ & $42 \pm 6$ & 0.30 \\
$\begin{array}{l}\text { Days of } \\
\text { hospitalization }\end{array}$ & $3.5 \pm 1$ & $3.5 \pm 0.8$ & 0.70 \\
\hline
\end{tabular}

required reintubation eight hours following surgery (five hours after the last opiate dose), due to $\mathrm{CO}_{2}$ retention. She was admitted and ventilated for two days in the intensive care unit. The rest of her postoperative course was uneventful. There were no postoperative complications and there was no need for reintubation and unplanned admission to the ICU in either group.

\section{Discussion}

In this prospective randomized, pilot study we sought to determine the incidence of postoperative respiratory events and pulmonary complications in patients undergoing laparoscopic sleeve gastrectomy surgery in relation to the type of muscle relaxant reversal agent. We have found that despite the deeper muscle relaxation before reversal in the sugammadex group, oxyhemoglobin saturation was higher with this reversal agent, supposedly indicating a more effective reversal effect as compared to neostigmine. It has to be noted that despite the statistical difference in $\mathrm{SpO}_{2}$, its clinical importance seems to be minimal. There were no postoperative complications and there was no need for unplanned admission to the ICU in either group. The use of such an effective and reliable agent (sugammadex) has special importance during laparoscopic bariatric surgery when high doses of muscle relaxant are required for optimal muscle relaxation [23, 27, 28].

We did not measure the effectiveness of sugammadex in the reversal of deep muscle relaxation as shown in previous studies [29-32] since all our patients required a TOF count of at least 2 twitches before reversal.

Sugammadex has been shown to provide effective and complete reversal of muscle relaxant agents [33, 34]; therefore, we speculate that the higher oxyhemoglobin saturations in the PACU in patients who received sugammadex may stem from a more effective reversal effect.

Despite the apparently evident advantages of sugammadex regarding its efficacy in reversal of aminosteroidal (i.e., rocuronium) muscle relaxants effects, in a prospective, partially randomized, placebo-controlled trial, Nemes et al. [35] concluded, based on their findings that pharmacological reversal did not prevent postoperative residual paralysis, irrespective of the reversal agent.

In conclusion, the use of sugammadex as compared to neostigmine following laparoscopic sleeve gastrectomy surgery was associated with higher postoperative oxyhemoglobin saturation despite deeper muscle relaxation (lower TOF count) before the administration of reversal agent. However, the clinical significance of this difference is questionable. Larger studies are required to elucidate the significance and the mechanism of better oxygenation after sugammadex reversal subsequent to sleeve gastrectomy surgery. The lack of statistical difference in the other variables measured may stem from the small patients' group sizes, since this was a pilot study.

\section{Conflict of interest}

Nothing to declare

\section{References}

1. Flegal KM, Carroll MD, Kit BK, Ogden CL. Prevalence of obesity and trends in the distribution of body mass index among US adults, 1999-2010. JAMA 2012; 307: 491-497. DOI: 10.1001/jama.2012.39

2. Chu NF. Prevalence of obesity in Taiwan. Obes Rev 2005; 6: 271-274. DOI: 10.1111/j.1467-789X.2005.00175.x

3. Haslam DW, James WP. Obesity. Lancet. 2005; 366: $1197-$ 2093. DOI: $10.1016 / \mathrm{S} 0140-6736(05) 67483-1$

Table 2. Train of four count before reversal administration and respiratory parameters recorded in the PACU*

\begin{tabular}{|llcc}
\hline Parameter & Neostigmine & Sugammadex & p \\
\hline TOF count before reversal administration & $3.5 \pm 0.6$ & $2.5 \pm 1$ & $<\mathbf{0 . 0 1}$ \\
${\text { Mean } \mathrm{SpO}_{2}}_{\text {Minimal } \mathrm{SpO}_{2}}$ & $95.8 \pm 0.01$ & $96.7 \pm 0.14$ & $<\mathbf{0 . 0 1}$ \\
\hline Respiratory rate breath/min & $93 \%$ & $94 \%$ & $<\mathbf{0 . 0 1}$ \\
$\%$ of patients with respiratory rate $<10 /$ min & $15 \pm 3$ & $15 \pm 2$ & 0.9 \\
$\%$ of patients with abnormal respiratory rate $<10$ or $>20 / \mathrm{min}$ & $8 \%$ & $0 \%$ & 0.27 \\
\hline
\end{tabular}

* Results are presented as means $\pm \mathrm{SD}$ or percentage 
4. Ali MR, Maguire MB, Wolfe BM. Assessment of obesity-related comorbidities: a novel scheme for evaluating bariatric surgical patients. J Am Coll Surg 2006; 202: 70-77. DOI: 10.1016/ j.jamcollsurg.2005.09.014

5. Berrington de Gonzalez A, Hartge P, Cerhan JR, Flint AJ, Hannan $\mathrm{L}$, MacInnis RJ, et al. Body-mass index and mortality among 1.46 million white adults. N Engl J Med 2010; 363: 2211-2219. DOI: 10.1056/NEJMoa 1000367

6. Kopelman PG. Obesity as a medical problem. Nature 2000; 404: 635-643. DOI: $10.1038 / 35007508$

7. Casati A, Putzu M. Anesthesia in the obese patient: pharmacokinetic considerations. J Clin Anesth 2005; 17: 134-145. DOI: $10.1016 /$ j.jclinane.2004.01.009

8. Lomanto D, Lee WJ, Goel R, Lee JJ, Shabbir A, So JB, et al. Bariatric surgery in Asia in last 5 years (2005-2009). Obes Surg 2012; 22: 502-506. DOI: 10.1007/s11695-011-0547-2

9. Buchwald H, Oien DM. Metabolic/bariatric surgery worldwide 2008. Obes Surg 2009; 19: 1605-1611. DOI: 10.1007/s11695009-0014-5

10. Shenkman Z, Shir Y, Brodsky JB. Perioperative management of the obese patient. Br J Anaesth 1993; 70: 349-359

11. Adams JP, Murphy PG. Obesity in anaesthesia and intensive care. Br J Anaesth 2000; 85: 91-108.

12. Fernandez AZ Jr, Demaria EJ, Tichansky DS, Kellum JM, Wolfe LG, Meador J, et al. Multivariate analysis of risk factors for death following gastric bypass for treatment of morbid obesity. Ann Surg 2004; 239(5): 698-702; discussion 702-703. DOI: 10.1097/01.sla.0000124295.41578.ab

13. Hines R, Barash PG, Watrous G, O'Connor T. Complications occurring in the postanesthesia care unit: a survey. Anesth Analg 1992; 74: 503-509

14. Plaud B, Debaene B, Donati F, Marty J. Residual paralysis after emergence from anesthesia. Anesthesiology 2010; 112: 10131022. DOI: $10.1097 /$ ALN.0b013e3181cded07

15. Murphy GS, Szokol J M, Marymont J H, Greenberg SB, Avram MJ, Vender JS. Residual neuromuscular blockade and critical respiratory events in the Postanesthesia Care Unit. Anesth Analg 2008; 107: 130-137. DOI: 10.1213/ane.0b013e31816d1268

16. Rose DK, Cohen MM, Wigglesworth DF, DeBoer DP. Critical respiratory events in postanesthesia care unit: patient, surgical, and anesthetic factors. Anesthesiology 1994; 81: 410-418

17. Murphy GS, Szokol JW, Avram MJ, Greenberg SB, Marymont $\mathrm{JH}$, Vender JS, et al. Intraoperative acceleromyography monitoring reduces symptoms of muscle weakness and improves quality of recovery in the early postoperative period. Anesthesiology 2011; 115: 946-954. DOI: 10.1097/ALN. 0b013e3182342840

18. Sauer M, Stahn A, Soltesz S, Noeldge-Schomburg G, Mencke T. The influence of residual neuromuscular block on the incidence of critical respiratory events. A randomised, prospective, placebo-controlled trial. Eur J Anaesthesiol 2011; 28: 842-848. DOI: $10.1097 /$ EJA.0b013e328345cd11

19. Arbous MS, Meursing AE, van Kleef JW, de Lange JJ, Spoormans $\mathrm{HH}$, Touw P, et al. Impact of anesthesia management characteristics on severe morbidity and mortality. Anesthesiology 2005; 102: 257-268

20. Hayes AH, Mirakhur RK, Breslin DS, Reid JE, McCourt KC. Postoperative residual block after intermediate-acting neuromuscular blocking drugs. Anaesthesia 2001; 56: 312-318. DOI: 10.1046/j.1365-2044.2001.01921.x

21. Berg H, Roed J, Viby-Mogensen J, Mortensen CR, Engbaek J, Skovgaard LT, et al. Residual neuromuscular block is a risk factor for postoperative pulmonary complications. A prospective, randomised, and blinded study of postoperative pulmonary complications after atracurium, vecuronium and pancuronium. Acta Anaesthesiol Scand 1997; 41: 1095-1103. DOI: 10.1111/ j.1399-6576.1997.tb04851.x

22. Gaszynski T, Szewczyk T, Gaszynski W. Randomized comparison of sugammadex and neostigmine for reversal of rocuroniuminduced muscle relaxation in morbidly obese undergoing general anaesthesia. Br J Anaesth 2012; 108: 236-239. DOI: 10.1093/ bja/aer330

23. Jones RK, Caldwell JE, Brull SJ, Soto RG. Reversal of profound rocuronium-induced blockade with sugammadex: a randomized comparison with neostigmine. Anesthesiology 2008; 109: 816824. DOI: $10.1097 /$ ALN.0b013e31818a3fee

24. Blobner M, Eriksson LI, Scholz J, Motsch J, Della Rocca G, Prins ME. Reversal of rocuronium-induced neuromuscular blockade with sugammadex compared with neostigmine during sevoflurane anaesthesia: results of a randomised, controlled trial. Eur J Anaesthesiol 2010; 27: 874-881. DOI: 10.1097/EJA. 0b013e32833d56b7

25. Khuenl-Brady KS, Wattwil M, Vanacker BF, Lora-Tamayo JI, Rietbergen H, Alvarez-Gómez JA. Sugammadex provides faster reversal of vecuronium-induced neuromuscular blockade compared with neostigmine: a multicenter, randomized, controlled trial. Anesth Analg 2010; 110: 64-73. DOI: 10.1213/ ane. $0 \mathrm{~b} 013 \mathrm{e} 3181 \mathrm{ac} 53 \mathrm{c} 3$

26. Lemmens HJ, El-Orbany MI, Berry J, Morte JB Jr, Martin G. Reversal of profound vecuronium-induced neuromuscular block under sevoflurane anesthesia: sugammadex versus neostigmine. BMC Anesthesiol 2010; 10: 15. DOI: 10.1186/1471-2253-10-15

27. Kirkegaard-Nielsen H, Helbo-Hansen HS, Lindholm P, Severinsen IK, Pedersen HS, Jensen EW. Optimum time for neostigmine reversal of atracurium-induced neuromuscular blockade. Can J Anaesth 1996; 43: 932-938. DOI: 10.1007/BF03011807

28. Gurusamy KS, Samraj K, Davidson BR. Low pressure versus standard pressure pneumoperitoneum in laparoscopic cholecystectomy. Cochrane Database Syst Rev 2009; (2): CD006930. DOI: 10.1002/14651858.CD006930.pub2

29. Fisher DM. Clinical pharmacology of neuromuscular blocking agents. Am J Health Syst Pharm 1999; 56(11 Suppl 1): S4-9

30. Sprague DH. Severe bradycardia after neostigmine in a patient taking propranolol to control paroxysmal atrial tachycardia. Anesthesiology 1975; 42: 208-210

31. Feinberg M. The problems of anticholinergic adverse effects in older patients. Drugs Aging 1993; 3: 335-348

32. Kopman AF, Eikermann M. Antagonism of non-depolarising neuromuscular block: current practice. Anaesthesia 2009; 64 Suppl 1: 22-30. DOI: 10.1111/j.1365-2044.2008.05867.x

33. Bom A, Epemolu O, Hope F, Rutherford S, Thomson K. Selective relaxant binding agents for reversal of neuromuscular blockade. Curr Opin Pharmacol 2007; 7: 298-302. DOI: 10.1016/ j.coph.2006.11.009

34. Abrishami A, Ho J, Wong J, Yin L, Chung F. Sugammadex, a selective reversal medication for preventing postoperative residual neuromuscular blockade. Cochrane Database Syst Rev 2009; (4): CD007362. DOI: 10.1002/14651858.CD007362.pub2

35. Nemes R, Fülesdi B, Pongrácz A, Asztalos L, Szabó-Maák Z, Lengyel $S$, et al. Impact of reversal strategies on the incidence of postoperative residual paralysis after rocuronium relaxation without neuromuscular monitoring: A partially randomised placebo controlled trial. Eur J Anaesthesiol 2016; [Epub ahead of print]. DOI: 10.1097/EJA.0000000000000585 